\title{
Analisis Potensi Likuefaksi dengan Berbagai Metode Berdasarkan Data Cone Penetration Test pada Jalan Tol Seksi II Probolinggo - Banyuwangi
}

\author{
AHMAD FARIS ALDZULFIKAR, IKHYA, DESTI SANTI PRATIWI \\ Program Studi Teknik Sipil, Institut Teknologi Nasional Bandung, Indonesia \\ Email: destisantipratiwi@itenas.ac.id
}

\begin{abstract}
ABSTRAK
Kerusakan infrastruktur yang terjadi di Indonesia bukan hanya diakibatkan oleh beban dinamis gempa, namun juga dipengaruhi oleh respon tanah di bawahnya ketika gempa terjadi, salah satu contohonya adalah fenomena likuefaksi. Proyek Pembangunan Jalan Tol Probolinggo Banyuwangi, Jawa Timur berada pada zona kerentanan likuefaksi sedang dan berada dekat dengan sesar Probolinggo yang memiliki pegerakan 0,2mm per tahun dan memiliki besar magnitudo 6.5 Mw. Penelitian ini dimaksudkan untuk mengukur potensi likuefaksi yang mungkin terjadi pada proyek pembangunan tol Probolinggo - Banyuwangi dengan menggunakan data Cone Penetration Test (CPT) berdasarkan metode analisis Shibata \& Terapaksa, Robertson \& Wride, Youd \& Idriss, Juang et. al dan Idriss \& Boulanger untuk mencari nilai rasio tegangan siklik (CSR) dan rasio tahanan siklik (CRR). Data pendukung lainnya pada analisis potensi likuefaksi ini adalah peta bahaya gempa 2017 dengan klasifikasi situs tanah lunak dan sedang. Hasil penelitian menunjukan bahwa jenis tanah yang terlikuefaksi adalah tanah pasir dan lanau kepasiran, jenis tanah ini sangat berpengaruh terhadap nilai CRR, sedangkan nilai CSR dipengaruhi oleh percepatan puncak gempa dan klasifikasi situs tanah.
\end{abstract}

Kata kunci: gempa, likuefaksi, metode analisis, CSR, CRR, CPT, percepatan puncak

\begin{abstract}
Infrastructure damages that have been found in Indonesia were not only caused by dynamic loads of earthquake, but also by the soil response underneath it while an earthquake occurs and one of it being a phenomenon called liquefaction. The project of Probolinggo-Banyuwangi Toll Road in East Java is within a moderate zone of liquefable soil, located near Probolinggo fault which is moving $0.2 \mathrm{~mm}$ every year, and a magnitude of $6.5 \mathrm{Mw}$. This research estimated the liquefaction potential of this project with the soil data obtained by Cone Penetration Test, analyzed by using the method of Shibata \& Terapaksa, Robertson \& Wride, Youd \& Idriss, Juang et. al and Idriss Boulanger, calculating the Cyclic Stress Ratio and Cyclic Resistance Ratio. This analysis of the potential of liquefaction used the map of earthquake in 2017 applied to soft and medium soil class. This research shows that the type of soil liquefied is sand soil and sandy silt soil. Both of these types gave a significant influence in calculating the CRR value, while the CSR value in influenced by the maximum acceleration of earthquake and the soil classification.
\end{abstract}

Keywords: earthquake, liquefaction, analysis method, CSR, CRR, CPT, maximum acceleration 


\section{PENDAHULUAN}

Proyek Pembangunan Jalan Tol Probolinggo-Banyuwangi, Jawa Timur yang merupakan lokasi penelitian berada pada zona kerentanan likuefaksi sedang dan berdekatan Sesar Probolinggo yang mengindikasikan pergerakan mendatar dengan pergerakan sebesar 0,2 $\mathrm{mm}$ per tahun dan besar Mw 6,5. Penelitian ini bertujuan untuk mengukur potensi terjadinya likuefaksi pada proyek tersebut dengan menggunakan data uji sondir/CPT (Cone Penetrometer Test) berdasarkan metode analisis [3], [4], [5], [6] dan [7] yang mengevaluasi nilai rasio tegangan siklik (CSR) dan rasio tahanan siklik (CRR). Nilai rasio tegangan siklik (CSR) dipengaruhi oleh percepatan puncak gempa, tegangan tanah, kedalaman muka air tanah dan faktor reduksi kedalaman, sedangnkan nilai rasio tahanan siklik (CRR) dipengaruhi oleh jenis, kekuatan dan konsistensi tanah (data hasil uji CPT / SPT).

\section{TINJAUAN PUSTAKA}

\subsection{Likuefaksi}

Likuefaksi adalah peristiwa dimana getaran di permukaan (gempa) mengakibatkan peningkatan air pori yang kemudian menyebabkan tanah akan kehilangan kekuatan dan bersifat cair (liquid) [1]. Secara umum, jenis tanah yang rentan terhadap likuefaksi adalah pasir lepas (loose sand) yang muka airnya tidak jauh dari permukaan tanah. Likuefaksi terjadi ketika nilai tegangan efek-tif dari tanah sama dengan nol [14].

\subsection{Analisis Likuefaksi Berdasarkan Data CPT}

Salah satu cara untuk mengetahui konsistensi tanah adalah dengan menggunakan data Cone Penetrometer Test (CPT) atau sondir [4]. Secara umum, prosedur perhitungan potensi likuefaksi terbagi dalam tiga tahapan yaitu perhitungan Rasio Tegangan Siklik (CSR) yang dihasilkan oleh beban gempa bumi, perhitungan Rasio Hambatan Siklik (CRR) yang dihitung berdasarkan hasil uji lapangan CPT / SPT, serta ana-lisis potensi likuefaksi dengan menghitung faktor keamanan setiap lapisan tanah granular. Faktor keamanan adalah rasio perbandingan dari CRR/CSR serta mengalikan faktor-faktor lainnya yang berpengaruh terhadap likuefaksi.

\subsection{Rasio Tegangan Siklik (Cyclic Shear Ratio)}

Rasio tegangan siklik adalah rasio tegangan yang dipicu oleh gempa bumi. Tegangan ge-ser yang dipicu ketika gempa bumi dihasilkan dari perambatan vertikal gelombang geser horizontal. Rasio tegangan siklik menurut [12] dapat dihitung dengan Persamaan 1.

$$
C S R=0,65 \frac{\sigma_{v_{0}}}{\sigma^{\prime} v_{0}} \frac{a_{\max }}{g} r_{d}
$$

\footnotetext{
halmana:

$C S R=$ rasio tegangan siklik,

$\sigma_{v o} \quad=$ tegangan total tanah,

$\sigma_{v o}^{\prime}=$ tegangan efektif tanah,

$a_{\max }=$ percepatan maksimum tanah,

$g=$ percepatan gravitasi $\left(9,81 \mathrm{~m} / \mathrm{s}^{2}\right)$,

$r_{d} \quad=$ faktor reduksi kedalaman.
} 


\subsection{Indeks Jenis Tanah (Soil Behavior Type Index)}

Indeks jenis tanah adalah korelasi empiris antara jenis dan data hasil pengujian Cone Penetrometer Test (CPT) [4]. Nilai indeks jenis tanah dapat dihitung secara iterasi dengan Persamaan 2.

$$
I_{c}=\left[(3,47-\log Q)^{2}+(1,22+\log F)^{2}\right]^{0,5}
$$

halmana:

$$
\begin{aligned}
Q & =\text { tahanan ujung yang telah dinormalisasi }=\left[\frac{q_{c}-\sigma_{v o}}{P_{a}}\right] \times\left[\frac{P_{a}}{\sigma_{v o}}\right]^{n}, \\
n & =1, \\
F & =\text { rasio gesek }=\left[\frac{F_{S}}{q_{c}-\sigma^{\prime} v_{0}}\right] \times 100 .
\end{aligned}
$$

Nilai indeks jenis tanah dapat digunakan untuk menentukan jenis perilaku tanah dengan menggunakan Tabel 1, serta untuk memperkirakan kandungan fines content pada tanah tersebut seperti pada Gambar 1.

Tabel 1. Batas-batas Jenis Tanah Berdasarkan Nilai $I_{c}$

\begin{tabular}{ccc}
\hline $\boldsymbol{I}_{\boldsymbol{c}}$ & Zone & Soil Behavior Type \\
\hline $\boldsymbol{I}_{\boldsymbol{c}}<1,31$ & 7 & Gravelly sand to dense sand \\
\hline $1,31<\boldsymbol{I}_{\boldsymbol{c}}<2,05$ & 6 & Sands: clean sand to silly sand \\
\hline $2,05<\boldsymbol{I}_{\boldsymbol{c}}<2,60$ & 5 & Sand mixtures: silly sand to sandy silt \\
\hline $2,60<\boldsymbol{I}_{\boldsymbol{c}}<2,95$ & 4 & Silt mixtures: clayed silt to silty clay \\
\hline $2,95<\boldsymbol{I}_{\boldsymbol{c}}<3,60$ & 3 & Clays: silty clay to clay \\
\hline $\boldsymbol{I}_{\boldsymbol{c}}>3,60$ & 2 & Organic soils: peats \\
\hline
\end{tabular}

(Sumber: Robertson, 1990)

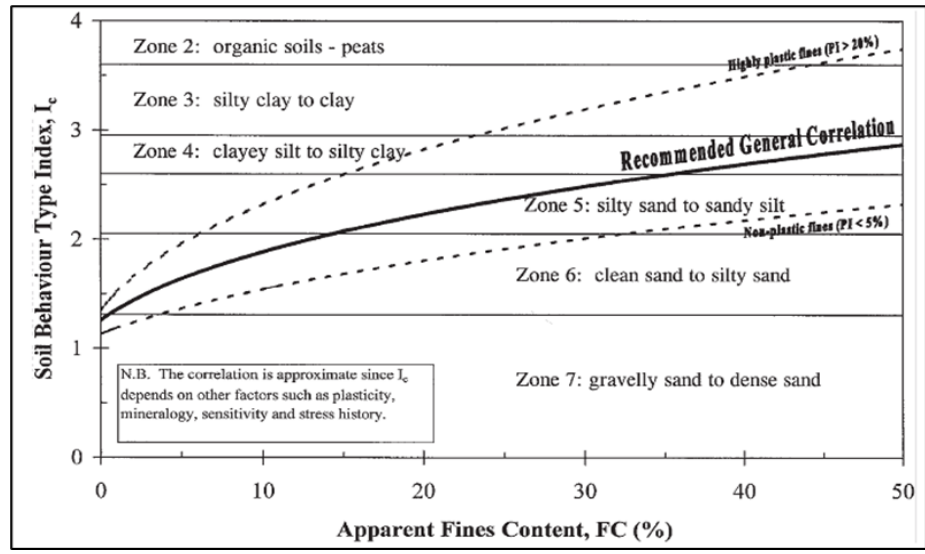

Gambar 1. Hubungan nilai $I_{c}$ dan perkiraan Fines Content (Sumber: Robertson \& Wride, 1998)

\subsection{Rasio Tahanan Siklik Berdasarkan Data CPT}

CPT memiliki conical penetrometer berdiameter $35,7 \mathrm{~mm}$ yang akan menekan masuk ke dalam tanah dengan laju $2 \mathrm{~cm} /$ detik; bersamaan dengan itu transducer akan mencatat gaya pada ujung konus dan gaya pada bagian selimut yang berada di belakang ujung konus. Gaya ujung dibagi dengan luas penampangnya adalah tahanan ujung $\left(q_{c}\right)$ dan gaya tahanan bagian selimut dibagi dengan luas selimutnya adalah tahanan friksi $\left(f_{s}\right)$. Dalam menghitung Rasio Tahanan Siklik berdasarkan data CPT, dua data tersebut yang selanjutnya menjadi faktor utama dalam menghitung nilai CRR. Metode analisis yang digunakan dalam penelitian adalah 
[3], [4], [5], [6] dan [7]. Secara umum terdapat perbedaan diantara kelima metode tersebut yang terangkum dalam Tabel 2.

Tabel 2. Rangkuman Perbedaan Metode yang Digunakan

\begin{tabular}{|c|c|c|c|c|c|}
\hline $\begin{array}{l}\text { Parameter } \\
\text { Perbandingan }\end{array}$ & S\&T (1989) & R\&W (1998) & Y\&I (2001) & J (2003) & I\&B (2014) \\
\hline $\begin{array}{l}\text { Menentukan } \\
\text { Jenis Tanah }\end{array}$ & $D_{50}$ & $I_{c}$ & $I_{c}$ & $I_{c}$ & $I_{c}$ \\
\hline $\begin{array}{l}\text { Parameter } \\
\text { Penentuan } \\
\text { Likuefaksi }\end{array}$ & Nilai $F K$ & Nilai $F K$ dan $I_{c}$ & Nilai $F K$ dan $I_{c}$ & Nilai $F K$ dan $I_{c}$ & Nilai $F K$ dan $F C \%$ \\
\hline $\begin{array}{l}\text { Output Data } \\
\text { Sondir yang } \\
\text { Digunakan }\end{array}$ & $q_{c}$ & $q_{c} \operatorname{dan} f_{s}$ & $q_{c} \operatorname{dan} f_{s}$ & $q_{c} \operatorname{dan} f_{s}$ & $q_{c} \operatorname{dan} f_{s}$ \\
\hline $\begin{array}{c}\text { Pengaruh } \\
\text { Besaran Gempa } \\
\text { (PGA dan } \\
\text { Magnitudo) }\end{array}$ & Ya & $\begin{array}{l}\text { Hanya pada tanah } \\
\text { pasir dan lanau, } \\
\text { Nilai } I_{C}<2,6\end{array}$ & $\begin{array}{l}\text { Hanya pada tanah } \\
\text { pasir dan lanau, } \\
\text { Nilai } I_{c}<2,6\end{array}$ & $\begin{array}{l}\text { Hanya pada tanah } \\
\text { pasir dan lanau, } \\
\text { Nilai } I_{c}<2,6\end{array}$ & $\begin{array}{c}\text { Hanya pada tanah } \\
\text { pasir dan lanau, } \\
\text { Nilai } F C \%<35 \%\end{array}$ \\
\hline $\begin{array}{c}\text { Pengaruh } \\
\text { Tegangan Tanah }\end{array}$ & Ya & Ya & Ya & Ya & Ya \\
\hline $\begin{array}{l}\text { Pengaruh Kelas } \\
\text { Situs Tanah }\end{array}$ & Ya & $\begin{array}{l}\text { Hanya pada tanah } \\
\text { pasir dan lanau, } \\
\text { Nilai } I_{c}<2,6\end{array}$ & $\begin{array}{l}\text { Hanya pada tanah } \\
\text { pasir dan lanau, } \\
\text { Nilai } I_{c}<2,6\end{array}$ & $\begin{array}{l}\text { Hanya pada tanah } \\
\text { pasir dan lanau, } \\
\text { Nilai } I_{C}<2,6\end{array}$ & $\begin{array}{c}\text { Hanya pada tanah } \\
\text { pasir dan lanau, } \\
\text { Nilai } F C \%<35 \%\end{array}$ \\
\hline
\end{tabular}

1. Metode Shibata \& Terapaksa (1998)

[3] mengusulkan metode analisis likuefaksi berdasarkan data sondir yang didapat dilapangan. Metode ini membandingkan antara tahanan ujung yang sudah dinormalisir $q_{c 1}$ dan rasio tegangan siklik dan dapat digunakan pada pasir bersih $\left(D_{50}>0,25\right)$ ataupun pasir kelanauan $\left(D_{50}<0,25\right)$ Bagan alir dari metode [3] dapat dilihat pada Gambar 2.

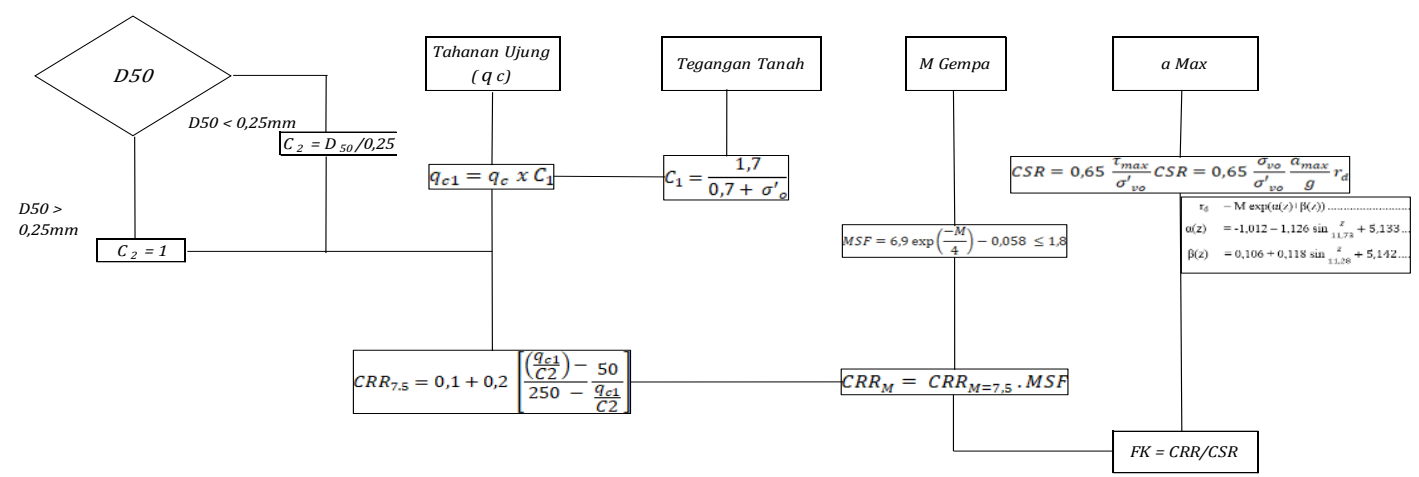

Gambar 2. Bagan alir analisis metode Shibata \& Terapaksa (1989)

2. Metode Robertson \& Wride (1998)

Metode ini merupakan perkembangan dari metode analisis berdasarkan data SPT yaitu menggunakan nilai perkiraan fines content. Pada metode ini nilai Indeks Jenis Tanah $\left(I_{c}\right)$ sangat diperlukan yang selanjutnya akan digunakan untuk mencari tahanan penetrasi tanah pada pasir bersih. Bagan alir metode [4] dapat dilihat pada Gambar 3. 


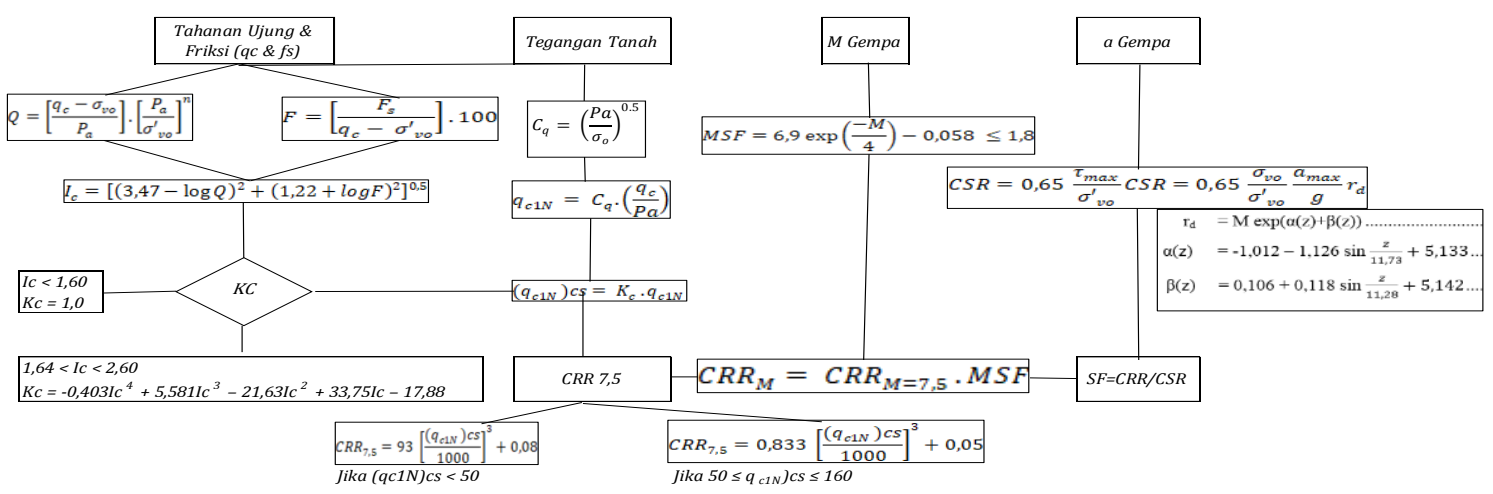

Gambar 3. Bagan Alir Analisis Metode Robertson \& Wride (1998)

3. Metode Youd \& Idriss (2001)

Metode ini adalah pengembangan dari metode [4]. prosedur untuk mencari nilai tahanan ujung ternormalisasi yang dikoreksi terhadap pasir bersih $\left(q_{c 1 N}\right) c s$ sama dengan metode tersebut. Yang membedakan adalah cara mencari nilai rasio tahanan siklik. Bagan alir dari metode [5] dapat dilihat pada Gambar 4.

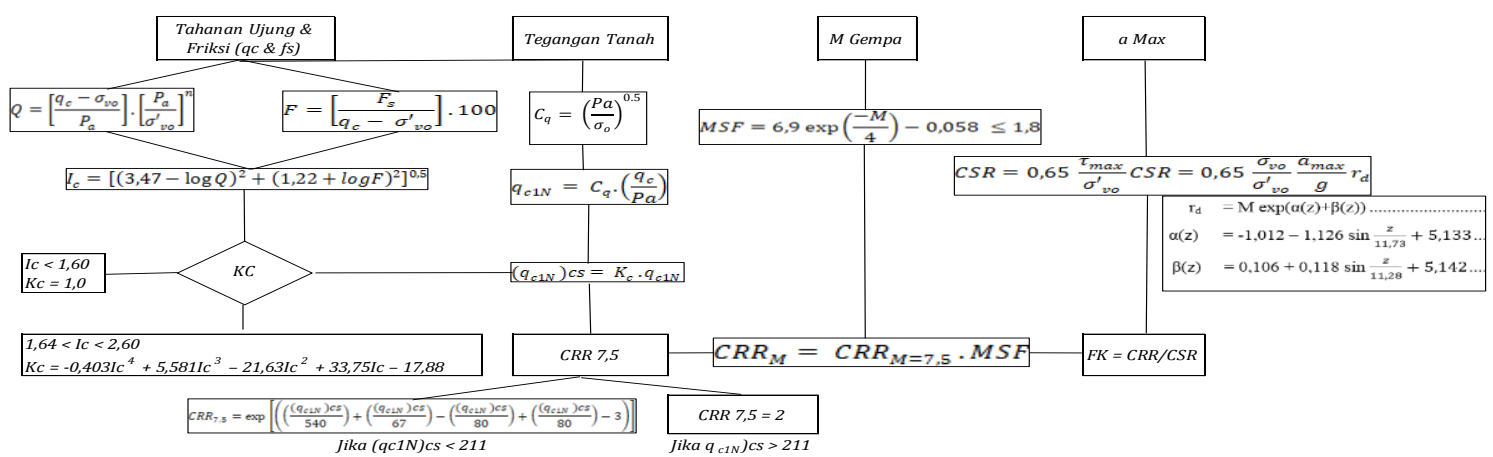

Gambar 4. Bagan Alir Analisis Metode Youd \& Idriss (2001)

4. Metode Juang et. al (2003)

[6] dalam [8] merumuskan batas-batas titik antara tanah yang terlikuefaksi dan yang tidak dalam grafik dua dimensi antara rasio tegangan siklik dan rasio tahaman siklik. Kemudian mereka mengembangkan persamaan empiris dengan dengan analisis regresi untuk mencari rasio tahanan siklik. Prosedur yang digunakan untuk mencari nilai tahanan ujung yang ternormalisasi dan terkoreksi pasir bersih $\left(q_{c 1 N}\right) c s$ adalah prosedur pada metode [4]. Bagan alir analisis metode [6] dapat dilihat pada Gambar 5.

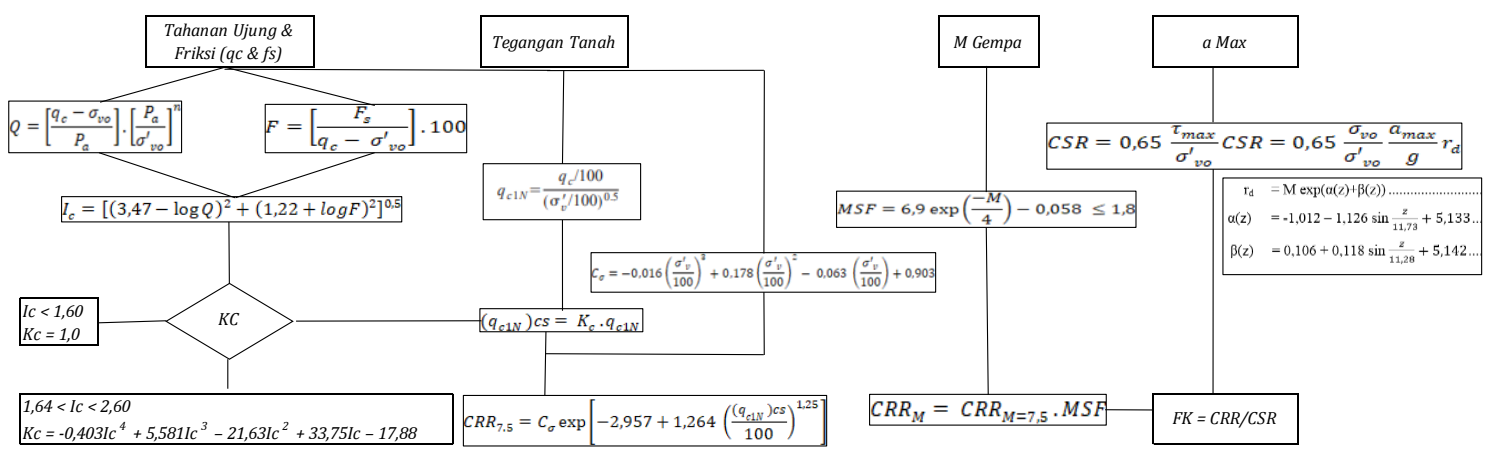

Gambar 5. Bagan Alir Analisis Metode Juang et al (2003) 
5. Metode Idriss \& Boulanger (2014)

Metode ini mempunyai perbedaan yang cukup signifikan dengan metode-metode sebelumnya dalam mencari tahanan ujung yang ternormalisasi dan terkoreksi pasir bersih $\left(q_{c 1 N}\right) c s$. Selain itu, pada metode ini juga dibutuhkan nilai perkiraan fines content $(F C \%)$ yang didapatkan dari korelasi nilai indeks jenis tanah $\left(I_{c}\right)$. Bagan alir analisis metode [7] dapat dilihat pada Gambar 6.

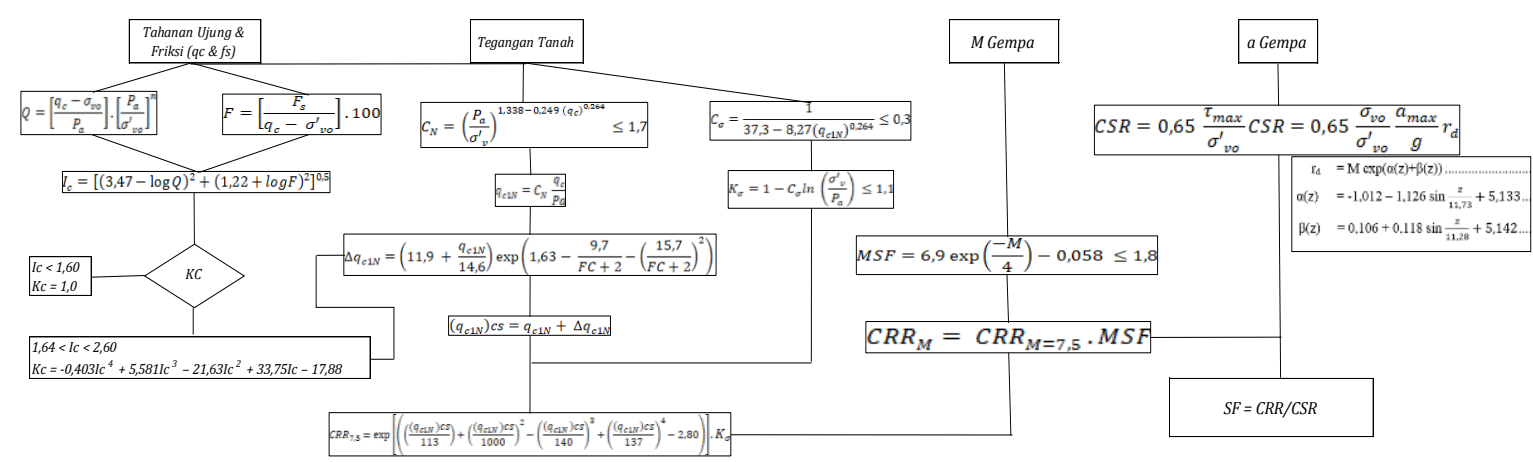

Gambar 6. Bagan Alir Analisis Metode Idriss \& Boulanger (2014)

\subsection{Magnitude Scale Factor(MSF)}

Magnitude Scale Factor (MSF) digunakan untuk mengkorelasikan nilai rasio siklik CSR dan/atau CRR dari yang konvensional yaitu $M=7,5$; karena nilai rasio siklik bergantung pada jumlah beban siklik yang berkorelasi dengan magnitudo $(M)[13]$.

Nilai MSF pada nilai magnitudo yang berbeda dapat dihitung dengan Persamaan 3 yang diusulkan oleh [11] sebagai berikut:

$$
M S F=6,9 \exp \left(\frac{-M}{4}\right)-0,058 \leq 1,8
$$

Sehingga nilai CRR dengan magnitudo selain $M=7,5$ dapat dihitung melalui pendekatan Persamaan 4 sebagai berikut:

$$
C R R_{M}=C R R_{7,5} \cdot M S F
$$

\subsection{Nilai Faktor Keamanan Terhadap Likuefaksi}

Safety factor/nilai keamanan terhadap likuefaksi merupakan hasil akhir dari analisis. Nilai $S F / F K$ didapatkan dari nilai tahanan siklik (CRR) dibagi dengan nilai rasio siklik (CSR) atau seperti pada Persamaan 5 berikut:

$$
S F=\frac{C R R}{C S R}
$$

Nilai $S F / F K$ dapat menentukan apakah suatu titik berpotensi terlikuefaksi atau tidak. Semakin besar nilai $S F / F K$ maka tanah pada kedalaman tersebut semakin tahan terhadap likuefaksi.

\subsection{Kondisi Kegempaan Probolinggo}

Sumber gempa terdekat dari Kota Probolinggo adalah Sesar Probolinggo. Sesar ini mempunyai gawir sesar yang memotong endapan lepas gunung api dari Gunung Argopuro dan morfologi dari gawir sesar ini mengindikasikan pergerakan mendatar dengan pergerakan sebesar 0,2 $\mathrm{mm}$ per tahun dan besar $\mathrm{Mw}$ 6,5. Berdasarkan peta kerentanan likuefaksi, Probolinggo memiliki nilai kerentanan likuefaksi sedang. 


\section{METODE PENELITIAN}

\subsection{Tahapan Penelitian}

Penelitian yang dilakukan dalam penelitian ini dilakukan secara bertahap dan sistematis dalam bentuk bagan alir yang ditunjukkan pada Gambar 7.

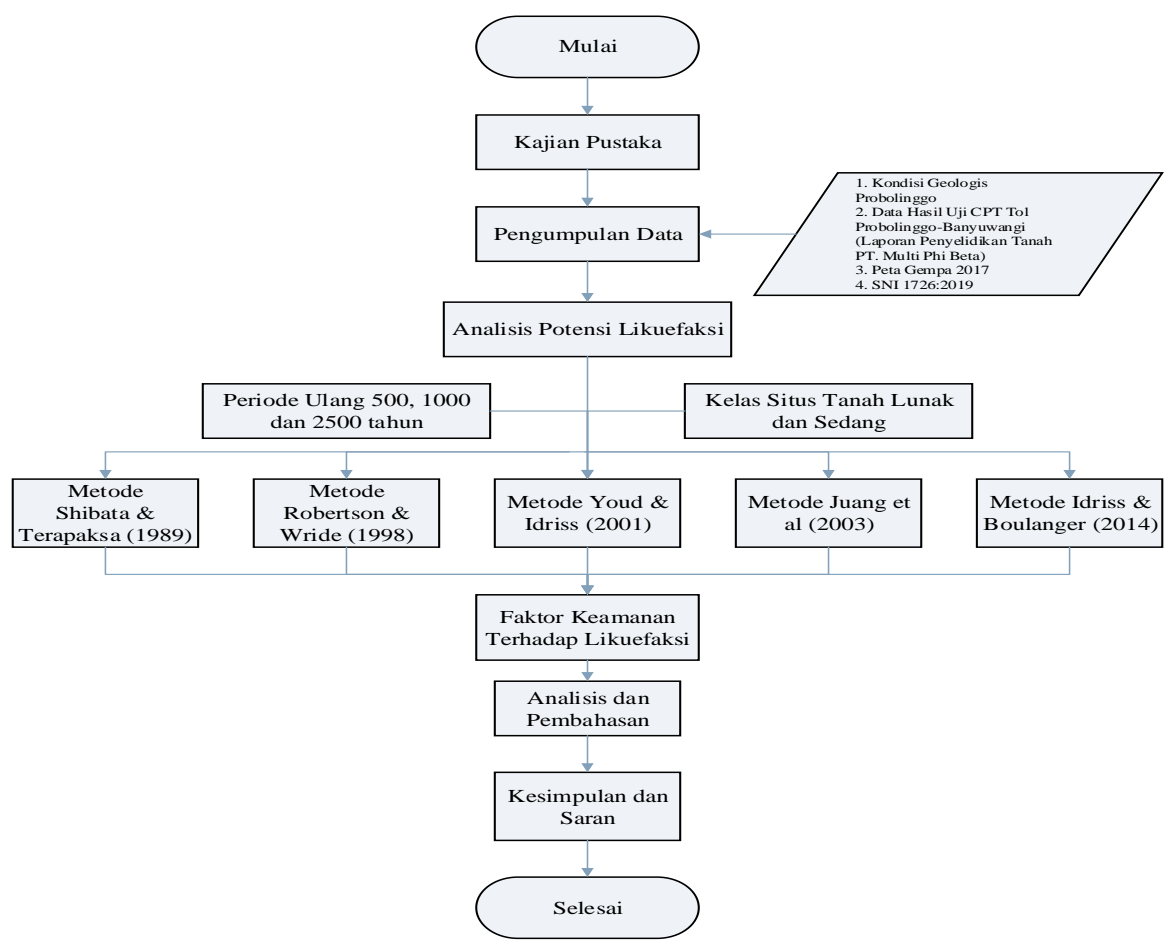

Gambar 7. Bagan alir penelitian

\subsection{Penetuan Lokasi Penelitian}

Lokasi yang ditinjau untuk penelitian analisis potensi likuefaksi ini terletak di Jalan tol Probolinggo - Banyuwangi Seksi 2 Jawa Timur. Jumlah titik yang ditinjau untuk dilakukan penelitian adalah sebanyak 10 titik yang tersebar sepanjang Jalan tol Probolinggo Banyuwangi Seksi 2 Jawa Timur.

\subsection{Pengumpulan Data}

Data yang diperlukan dalam penelitian ini adalah data hasil uji Sondir/CPT (Cone Penetrometer Test) yang diambil dari lokasi penelitian dengan menggunakan alat Sondir/CPT mekanik, namun untuk keperluan analisis data nilai tahanan ujung $\left(q_{c}\right)$ dan tahanan friksi $\left(f_{s}\right)$ yang didapat dari lapangan dikoreksi terlebih dahulu kedalam nilai sondir elektrik [10]. Selanjutnya, peta bahaya gempa yang digunakan adalah peta gempa tahun 2017, dengan data yang digunakan adalah nilai PGA (Peak Ground Acceleration) kemungkinan telampaui 10\% dalam 50 tahun, $7 \%$ dalam 75 tahun dan $2 \%$ dalam 50 tahun untuk kelas situs tanah lunak dan sedang.

\subsection{Analisis Potensi Likuefaksi Berdasarkan Data Hasil Uji CPT}

Setelah mendapatkan hasil data sondir/CPT (Cone Penetrometer Test) di lokasi penelitian, selanjutnya analisis dilakukan untuk mengetahui di titik mana saja potensi likuefaksi akan terjadi pada lokasi penelitian. Metode analisis yang penulis gunakan adalah metode analisis potensi likuefaksi yang didasarkan pada data hasil sondir/CPT [3], [4], [5], [6] dan [7]. 


\section{ANALISIS DAN PEMBAHASAN}

\subsection{Percepatan Puncak Batuan Dasar}

Nilai Percepatan Puncak Batuan Dasar didapat dari Buku Peta Bahaya Gempa 2017 pada periode ulang gempa 500, 1.000 dan 2.500 tahun yang kemudian disesuaikan dengan kelas situs tanah lunak dan sedang sesuai dengan SNI 1726:2019 seperti pada Tabel 3.

Tabel 3. Nilai Percepatan Puncak Batuan Dasar Dasar Terkoreksi Kelas Situs (PGAm)

\begin{tabular}{ccc}
\hline $\begin{array}{c}\text { Periode Ulang } \\
\text { (Tahun) }\end{array}$ & Tanah Lunak & Tanah Sedang \\
\hline 500 & 0,3225 & 0,225 \\
\hline 1.000 & 0,380 & 0,280 \\
\hline 2.500 & 0,525 & 0,4375 \\
\hline
\end{tabular}

\subsection{Hasil Perbandingan Metode Analisis}

Hasil analisis potensi likuefaksi pada titik BH 45800; CPT 45850 untuk semua metode dengan periode ulang 500 tahun dan kelas situs Soft Soil ditunjukan pada Gambar 9.

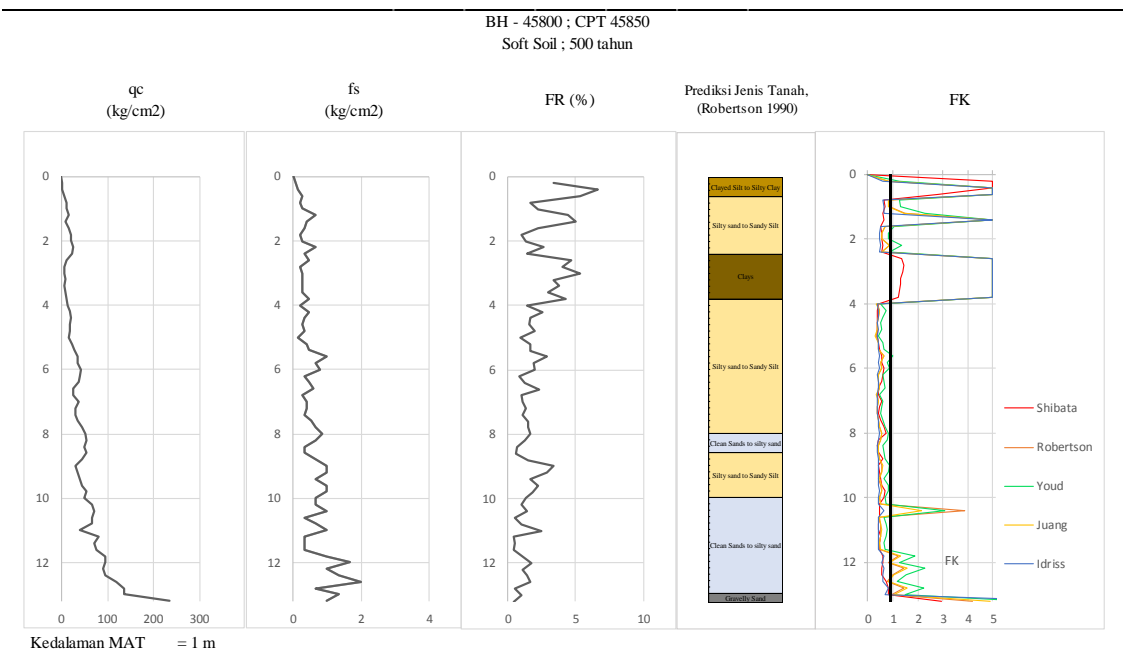

Gambar 9. Hasil perbandingan metode analisis

Pada titik BH 45800; CPT 45850 dengan periode ulang 500 tahun dan kelas situs Soft Soil potensi likuefaksi berada pada kedalaman $4 \mathrm{~m}-13 \mathrm{~m}$. Nilai FK yang tertinggi didapat dari metode [5] sedangkan yang terendah didapat dari metode [7]. Metode [4], [5] dan [6] cenderung memiliki garis tren yang serupa, ini dikarenakan nilai faktor keamanan (FK) ketiga metode tersebut sangat dipengaruhi oleh indeks jenis tanah $\left(I_{c}\right)$ yang dikemukakan [9], sedangkan pada metode [7] nilai Indeks Jenis Tanah $\left(I_{c}\right)$ dikonversikan lagi kedalam nilai $F C \%$ sebelum mendapatkan nilai faktor keamanan (FK) dan pada metode [3] nilai faktor keamanan (FK) dipengaruhi oleh ukuran diameter rata-rata $\left(D_{50}\right)$ yang dikorelasikan dari prediksi jenis tanah, pada metode ini tidak menutup kemungkinan likuefaksi terjadi di tanah lempung campuran pada gempa yang besar. Selebihnya, seluruh metode dipengaruhi oleh nilai tahanan ujung $\left(q_{c}\right)$, tahanan friksi $\left(f_{s}\right)$ dan nilai tegangan vertikal efektif tanah $\left(\sigma^{\prime}\right)$.

\subsection{Hasil Perbandingan Variasi Periode Ulang Gempa}

Hasil analisis yang digunakan untuk membandingkan bagaimana perngaruh periode ulang terhadap nilai keamanan (FK) adalah hasil analisis pada lokasi titik tinjau BH 45800; CPT 45850 untuk masing-masing kelas situs tanah seperti ditunjukkan pada Gambar 10 dan Gambar 11. 


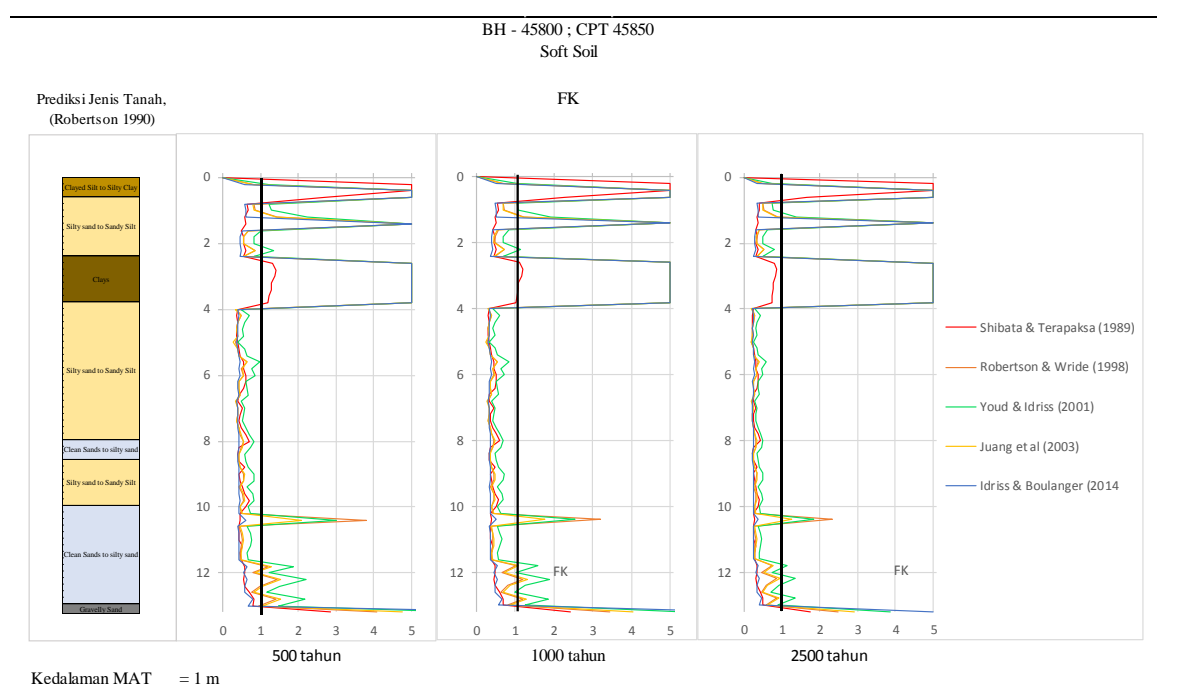

Gambar 10. Hasil perbandingan variasi periode ulang gempa tanah lunak

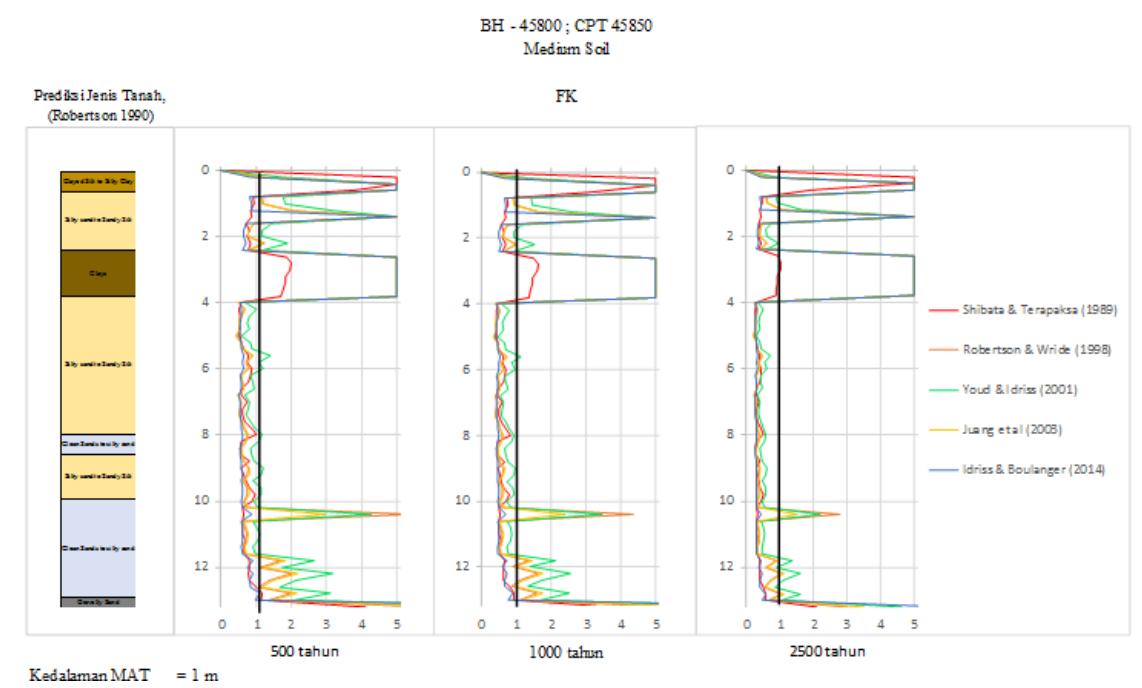

Gambar 11. Hasil perbandingan variasi periode ulang gempa tanah sedang

Gambar 10 menunjukkan bahwa pada kelas situs tanah Soft Soil, nilai faktor keamanan (FK) pada periode ulang 500 tahun $17,8 \%$ lebih besar daripada nilai faktor keamanan (FK) pada periode ulang 1.000 tahun dan $62,8 \%$ lebih besar daripada periode ulang 2.500 tahun. Sedangkan, nilai faktor keamanan (FK) pada periode ulang 1.000 tahun 38,2\% lebih besar daripada periode ulang 2.500 tahun sedangkan Gambar 11 menunjukkan bahwa pada kelas situs tanah Medium Soil, nilai faktor keamanan (FK) pada periode ulang 500 tahun $24,4 \%$ lebih besar daripada nilai faktor keamanan (FK) pada periode ulang 1.000 tahun dan $94,4 \%$ lebih besar daripada periode ulang 2.500 tahun. Sedangkan, nilai faktor keamanan (FK) pada periode ulang 1.000 tahun $56,25 \%$ lebih besar daripada periode ulang 2.500 tahun.

\subsection{Hasil Perbandingan Variasi Kelas Situs Tanah}

Hasil Analisis yang digunakan untuk membandingkan bagaimana perngaruh kelas situs tanah terhadap nilai keamanan (FK) adalah hasil analisis pada lokasi titik tinjau BH 45800; CPT 45850 untuk masing-masing periode ulang gempa seperti ditunjukkan pada Gambar 12 sampai Gambar 14. 


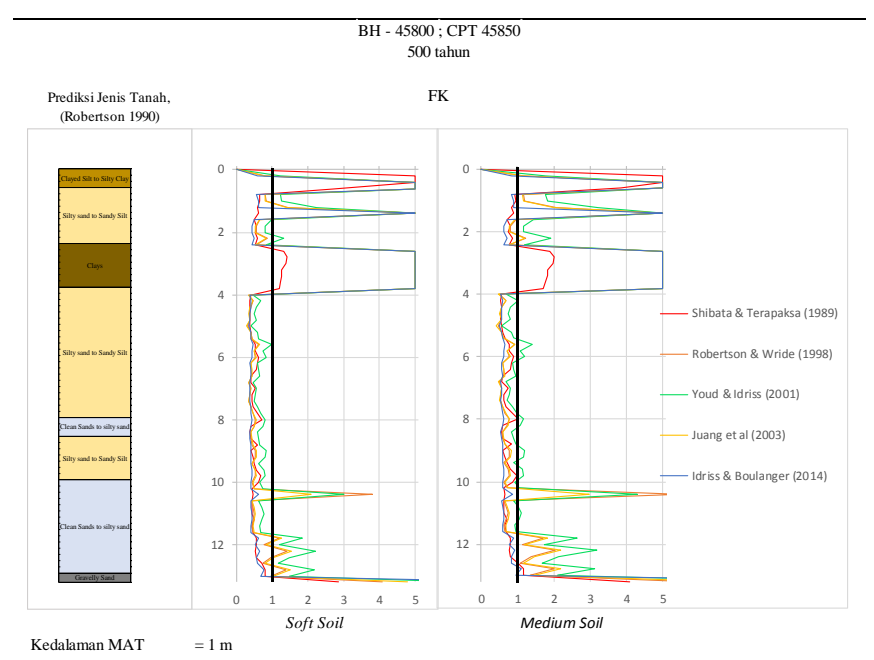

Gambar 12. Hasil perbandingan variasi kelas situs tanah; 500 tahun

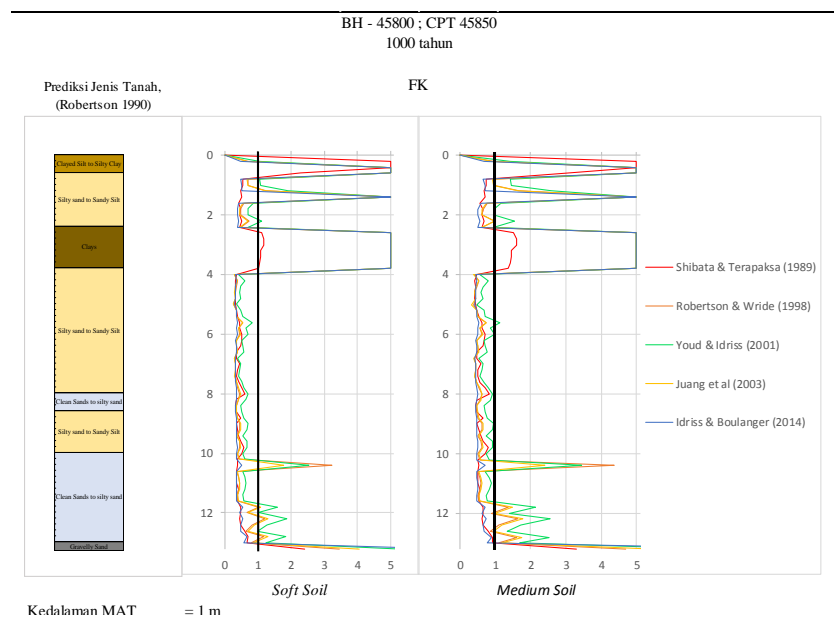

Gambar 13. Hasil perbandingan variasi kelas situs tanah; 1.00 tahun

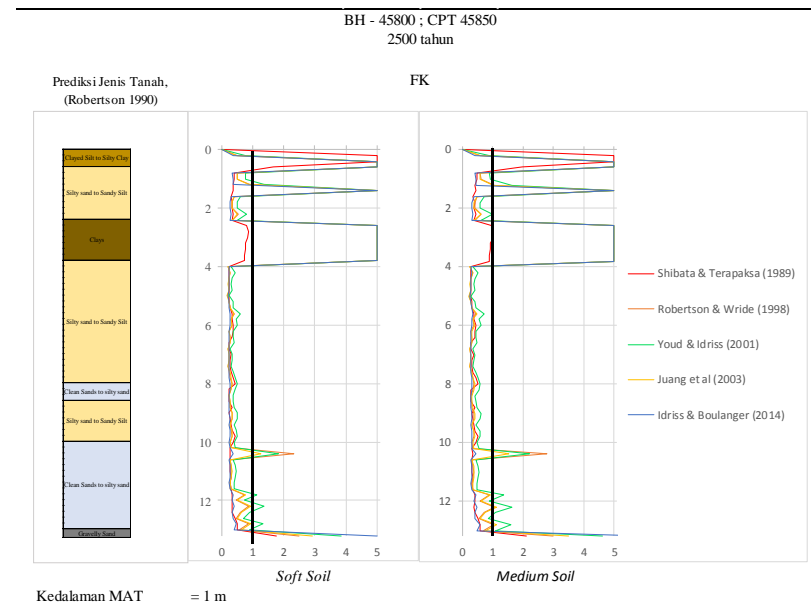

Gambar 14. Hasil perbandingan variasi kelas situs tanah; 2.500 tahun

Pada Gambar 12 terlihat bahwa nilai faktor keamanan (FK) yang dihasilkan pada kelas situs Medium Soil lebih besar 43,3\% daripada nilai faktor keamanan (FK) pada kelas situs Soft Soil yang disebabkan oleh nilai percepatan puncak batuan dasar ( $P G A m$ ) yang lebih besar pula, Gambar 13 menghasilkan faktor keamanan (FK) pada kelas situs Medium Soil tanah lebih besar 35,7\% daripada nilai faktor keamanan (FK) pada kelas situs Soft Soil yang disebabkan oleh nilai percepatan puncak batuan dasar ( $P G A m)$ yang lebih besar pula, dan Gambar 14 
menghasilkan nilai faktor keamanan (FK) pada kelas situs Medium Soil tanah lebih besar $20 \%$ daripada nilai faktor keamanan (FK) pada kelas situs Soft Soil yang disebabkan oleh nilai percepatan puncak batuan dasar $(P G A m)$ yang lebih besar pula.

\section{KESIMPULAN}

Berdasarkan hasil analisis potensi likuefaksi berdasarkan data CPT yang telah dilakukan dapat disimpulkan bahwa:

1. Nilai $q_{c}$ pada lokasi titik tinjau berkisar antara $0 \mathrm{~kg} / \mathrm{cm}^{2}-260 \mathrm{~kg} / \mathrm{cm}^{2}$ dan jenis tanah pada lokasi titik tinjau didominasi oleh pasir kelanauan dan lanau berlempung.

2. Potensi likuefaksi berada pada jenis tanah pasir hingga lanau yang memiliki nilai $q_{c}$ hingga $120 \mathrm{~kg} / \mathrm{cm}^{2}$.

3. Potensi Ikuefaksi pada lokasi titik tinjau terjadi hingga kedalaman $22,8 \mathrm{~m}$.

4. Dari 5 (lima) metode analisis yang digunakan menunjukan kekompakan hasil terhadap tanah pasir yang berpotensi likuefaksi, namun terdapat perbedaan pada tanah yang tidak berpotensi likuefaksi yang disebabkan sensitivitas metode tersebut pada jenis tanahnya.

5. Nilai Faktor Keamanan (FK) tertinggi dihasilkan oleh metode Youd (2001) sedangkan nilai Faktor Keamanan (FK) terkecil dihasilkan oleh Metode Idriss \& Boulanger (2014).

6. Metode Robertson \& Wride (1998), Youd \& Idriss (2001) dan Juang et al (2003) memiliki kemiripan dalam hasil analisis karena menjadikan nilai Indeks Jenis Tanah $\left(I_{c}\right)$ sebagai parameter awal untuk mendeteksi likuefaksi (jika $I_{c}>2,6$ tidak terjadi likuefaksi; tanpa menghitung nilai FK).

7. Metode Idriss \& Boulanger (2014) menjadikan nilai Fines Content (FC\%) sebagai parameter awal pendeteksi likuefaksi, hal ini menyebabkan sedikit perbedaan pada garis tren hasil analisis dibandingkan tiga metode sebelumnya (jika $\mathrm{FC} \%>35 \%$ tidak terjadi likuefaksi, tanpa menghitung nilai FK).

8. Metode Shibata \& Terapaksa (1989) menjadikan nilai FK sebagai satu-satunya parameter likuefaksi dengan memasukan $D_{50}$ sebagai salah satu parameter perhitungan, hal ini menyebabkan perbedaan yang cukup signifikan pada garis tren hasil analisis dibandingkan empat metode lainnya dan tidak menutup kemungkinan tanah lempung campuran akan terlikuefaksi pada gempa yang besar.

9. Nilai Faktor Keamanan (FK) terhadap likuefaksi pada kelas situs tanah Medium Soil lebih tinggi daripada kelas situs tanah Soft Soil.

10. Nilai Faktor Keamanan (FK) terhadap likuefaksi berbanding terbalik dengan periode ulang gempa, semakin besar periode ulang gempa nilai FK akan semakin kecil.

\section{DAFTAR PUSTAKA}

[1] Day, R.W. (2001). Geotechnical Earthquake Engineering Handbook. New York: McGrawHill Companies.

[2] Shibata, T., \& Teparaska, W. (1988). Evaluation of liquefaction potentials of soils using cone penetration tests. Soils and Foundations.

[3] Robertson, P.K., \& Wride, C.E. (1998). Evaluating cyclic liquefaction potential using the cone penetration test. Ottawa: Can. Geotech. J.,

[4] Youd, T.L., Idriss, I.M., et al. (2001) Simplified procedure for evaluating soil liquefaction potential, J J. Geotech. Geoenviron, ASCE, 97(9), 1249-1273.

[5] Seed, H.B, Idriss, I.M., et al. (1971) Liquefaction resistance of soils: summary report from the 1996 NCEER and 1998 NCEER/NSF workshops on evaluation of liquefaction resistance of soils, J. Geotechnical and Geoenvironmental Eng. 
[6] Juang, C.H., Yuan, H., Lee, De., \& Lin, P.S. (2003). Simplified Cone Penetration Test-based Method for Evaluating Liquefaction Resistance of Soils. J. Geotech. Geoenviron.

[7] Boulanger, R.W., \& Idriss, I.M. (2014). CPT and SPT based liquefaction triggering procedures. Rep. No. UCD/CGM-14/01, Univ. of California, Davis, CA.

[8] Pirhadi, N., Tang, X., Yang, Q., \& Kang, F. (2019). A New Equation to Evaluate Liquefaction Triggering Using the Response Surface Method and Parametric Sensitivity Analysis. Sustainability (2071-1050), 11(1), pp. _- -

[9] Robertson, P.K. (1990). Soil classification using CPT, Can. Geotech. J., Ottawa, 27(1), 151158.

[10] Facciorusso, J., Madiai, C., \& Vannucchi, G. (2016). The 2012 Emilia earthquake (Italy): Geotechnical characterization and ground respone analyses of the paleo-Reno river levees, Soil Dynamics and Earthquake Engineering, 86, 71-88.

[11] Idriss, I.M. (1999). Presentation notes: An update of the Seed-Idriss simplified procedure for evaluating liquefaction potential, Proc., TRB Workshop on New Approaches to Liquefaction Anal., Publ. No. FHWARD-99-165, Federal Highway Administration, Washington, D.C.

[12] Seed, H. B., and Idriss, I. M. (1971). 'Simplified procedure for evaluating soil liquefaction potential. J. Soil Mech. and Found. Div., ASCE, 97(9), 1249-1273.

[13] Idriss, I. M., \& Boulanger, R. W. (2008). Soil liquefaction during earthquakes. Monograph MNO-12, Earthquake Engineering Research Institute, Oakland, CA, 261 pp

[14] Ishihara, K., Yamazaki, A., \& Haga, K. (2008). Liquefaction of Ko-consolidated sand under cyclic rotation of proncipal stress direction with lateral constraint. Soil and Foundations, Japanese Society of Soil Mechanics and Foundation Engineering, 25(4), 63-74 